\title{
ESTUDIO QUÍMICO BROMATOLÓGICO Y SCREENING FITOQUÍMICO DEL FRUTO DE Pourouma cecropiifolia C. MARTIUS "UVILLA"
}

\author{
Bromatological chemical study and phytochemical screening of fruit from Pourouma \\ cecropiifolia c. Martius "uvilla" \\ Gladys C. Arias Arroyo \\ Laboratorio de Bromatología, Facultad de Farmacia y Bioquímica, Universidad Nacional Mayor de San Marcos
}

\begin{abstract}
RESUMEN
La especie Pourouma cecropiifolia C. Martius "uvilla", cuyo hábitat es principalmente el trópico, también es conocida con los nombres de "uvilla", "uva caimarona", "caimarón", "caima" y "puruma". Presenta un contenido de agua de 84,50 gramos por ciento. En base seca, en gramos por ciento, presenta: extracto etéreo 1,87; proteína total 2,06; ceniza 1,81; fibra cruda 5,42 y carbohidratos 88,84. En base seca, en miligramos por ciento: vitamina B1 o,58; vitamina B2 1,42; niacina 1,94 y vitamina C 31,0. También presenta en base seca, en miligramos por ciento: calcio 154,84; hierro 3,87 y fósforo 64,52. En el screening fitoquímico se detectó la presencia de compuestos fenólicos, flavonoides, taninos, alcaloides y esteroides.
\end{abstract}

Palabras clave: Pourouma cecropiifolia, uvilla, químico bromatológico, frutos, screening fitoquímico.

\section{SUMMARY}

The specie Pourouma cecropiifolia C.martius (Uvilla), whose habitat is the tropic, it is also known as "uvilla", "uva caimanera", “ caimaron”, "caima” y "puruma “. It presents content of water 84,50 grams percent. In dry sample: ethereal extract 0,91 ; total protein 2,06; ash 1,81; crude fiber 5,42; carbohydrates 88,84 grams percent. Vitamin B1 0,58 ; vitamin B2 1,42; vitamin $C$ 3,10 milligrams percent. Also are present in dry sample: calcium 154,84; hierro 3,87; phosphorus 64,52 milligrams percents.

It is a fruit which can be used as important source of nutrients, mainly vitamins $\mathrm{C}, \mathrm{B}_{1}, \mathrm{~B}_{2}$ and the minerals such as calcium, phosphorus and iron. The phytochemical screening have detected the presence of phenolic compounds, flavonoids, tannins, alkaloids y steroids.

Keywords: Pourouma cecropiifolia, chemical bromatological, fruit, phytochemical screening.

\section{INTRODUCCIÓN}

A lgunos de los problemas que afronta el mundo son: el hambre, la desnutrición y las enfermedades; por lo que es necesario contribuir al conocimiento y estudio de nuevas fuentes alimentarias y medicinales.

En las zonas tropicales y subtropicales del mundo hay aproximadamente 950 especies productoras de frutos comestibles y, de éstas, 200 son de suficiente calidad como para ser aprovechadas en cantidades comerciales.

Nuestro país cuenta con ingentes recursos naturales que requieren ser estudiados. Tal es el caso de la uvilla, fruto muy apreciado por los lugareños en cada zona por su sabor exótico y por sus propiedades terapéuticas.
Este es un frutal de la Amazonía, donde se encuentra el mayor número de plantas, fundamentalmente en la zona de la Selva Baja ${ }^{(1)}$, en Bolivia, Colombia, Ecuador y Perú. Esta especie se distribuye naturalmente en la cuenca alta del río Amazonas. Se cultiva en los departamentos de Loreto, Ucayali, San Martín, Madre de Dios, Huánuco, Pasco y Junín. Conocida también con los nombres de "uvilla", "uva caimarona", "caimaron", "caima", "mapati", "cucura" y "puruma" $(2,3)$. La fruta se consume fresca por su sabor dulce y agradable. También se utiliza para hacer vino y jalea. Algunos emplean las semillas molidas como sustituto del café.

En el presente trabajo se ha realizado el estudio químico bromatológico y el screnning fitoquímico del fruto. 
Tabla 1. Composición centesimal del fruto de Pourouma cecropiifolia C. Martius "uvilla".

\begin{tabular}{lcc}
\hline & $\begin{array}{c}\text { Muestra en } \\
\text { base seca }\end{array}$ & $\begin{array}{c}\text { Muestra } \\
\text { fresca }\end{array}$ \\
\cline { 2 - 3 } & \multicolumn{2}{c}{$\mathbf{g \%}$} \\
\hline Humedad & --- & 84,50 \\
Extracto etéreo & 1,87 & 0,29 \\
Proteína total $\left({ }^{*}\right)$ & 2,06 & 0,32 \\
Fibra cruda & 5,42 & 0,84 \\
Ceniza & 1,81 & 0,28 \\
Carbohidrato & 88,84 & 13,77 \\
Valor Calórico $\left(^{* *}\right)$ & 412,90 & 64,00 \\
\hline
\end{tabular}

* Factor de proteína $=6,25^{* *}$ Valor expresado en kilocalorías

\section{MATERIALES Y MÉTODOS}

Pourouma cecropiifolia "uvilla" fue recolectadAen Yarinacocha, Pucallpa, Perú. Para la determinación químico bromatológica y el screening fitoquímico se utilizó el fruto. La humedad, proteína, grasa, ceniza y fibra fueron determinados utilizando los métodos de la AOAC (4). El factor utilizado para calcular proteína fue 6,25. Los carbohidratos fueron obtenidos por diferencia, es decir sustrayendo de 100 la suma de humedad, proteína, grasa, ceniza y fibra. Los minerales fueron determinados utilizando los métodos analíticos por espectrofotometría de absorción atómica. La determinación de vitamina $B_{1}$ fue realizada utilizando el método del tiocromo, vitamina $B_{2}$ por el método fluorométrico y niacina por el método químico ${ }^{(5)}$. La vitamina $C$ se determinó por el método de titulación con el 2,6-diclorofenolindofenol ${ }^{(4)}$.

El screening fitoquímico en los extractos se realizó siguiendo la marcha fitoquímica general ${ }^{(6,7)}$.

\section{RESULTADOS}

En la tabla 1 se muestra la composición química del fruto de Pourouma cecropiifolia "uvilla"; observándose que presenta 5,42; 2,06; 1,87 y 88,84 g\% en base seca de fibra cruda, proteína total, extracto etéreo y carbohidratos, respectivamente. En la tabla 2 se muestra un contenido de calcio de $154,84 \mathrm{mg} \%$, en base seca. En la tabla 3 se observan las cantidades de vitaminas destacando la vitamina B1 y en la tabla 4 se

Tabla 3. Vitaminas en el fruto de Pourouma cecropiifolia C. Martius "uvilla"

\begin{tabular}{lcc}
\hline & $\begin{array}{c}\text { Muestra en base } \\
\text { seca }\end{array}$ & $\begin{array}{c}\text { Muestra } \\
\text { fresca }\end{array}$ \\
\cline { 2 - 3 } & \multicolumn{3}{c}{ mg\% } \\
\hline Vitamina B1 & 0,58 & 0,09 \\
Vitamina B2 & 1,42 & 0,22 \\
Niacina & 1,94 & 0,30 \\
Vitamina C & 31 & 4,89 \\
\hline
\end{tabular}

Tabla 2. Contenido de minerales en el fruto de Pourouma cecropiifolia C. Martius "uvilla"

\begin{tabular}{lcc}
\hline & $\begin{array}{c}\text { Muestra en base } \\
\text { seca }\end{array}$ & $\begin{array}{c}\text { Muestra } \\
\text { fresca }\end{array}$ \\
\cline { 2 - 3 } & \multicolumn{3}{c}{$\mathbf{m g} \%$} \\
\hline Calcio & 154,84 & 24,00 \\
Fósforo & 64,52 & 10,00 \\
Hierro & 3,87 & 0,60 \\
\hline
\end{tabular}

destaca la presencia de compuestos fenólicos en mayor cantidad.

\section{DISCUSIÓN}

De acuerdo a los valores encontrados, expresados en base seca, la uvilla presenta un contenido de calcio de $154,84 \mathrm{mg} \%$, menor que el camu-camu, aproximado al capulí y al aguaje, mayor que la tuna y el pijuayo. El valor de fósforo $(64,52 \mathrm{mg} \%$ ) fue aproximado al aguaje, menor que el de la tuna y capulí y más bajo que el del camu camu. Respecto al hierro (3,87 mg\%), fue menor que en el capulí y camu camu. Los valores de tiamina y riboflavina fueron mayores que en el camu camu, capulí, pijuayo, aguaje y tuna. La niacina $1,94 \mathrm{mg} \%$ fue menor que camu camu, capulí, pijuayo y tuna, pero mayor que que en el aguaje.

De los datos obtenidos se comprueba el importante valor nutritivo y un valor calórico de 64,0 y 412,90 kilocalorias en el fruto fresco y en el extracto seco, respectivamente.

En la tabla 4 se presentan los resultados del screening fitoquímico para la detección de metabolitos secundarios en el extracto de Pourouma cecropiifolia C. Martius "uvilla", encontrándose que contiene compuestos fenólicos, flavonoides, taninos y en menor cantidad alcaloides y esteroides.

\section{CONCLUSIÓN}

Pourouma cecropiifolia C. Martius "uvilla", presenta un contenido de agua de 84,50 gramos por ciento. En base seca, en gramos por ciento, presenta: extracto etéreo 1,87 ; proteína total 2,06 ; ceniza 1,81 ;

Tabla 4. Screening fitoquímico del fruto de Pourouma cecropiifolia C. Martius "uvilla"

\begin{tabular}{lcc}
\hline \multicolumn{1}{c}{ Metabolitos } & Reactivo & $\begin{array}{c}\text { Extracto } \\
\text { metanólico }\end{array}$ \\
\hline Compuestos fenólicos & Cloruro Férrico & +++ \\
Flavonoides & Sh Shinoda & ++ \\
Taninos & Gelatina & ++ \\
Alcaloides & Dragendorff & + \\
Alcaloides & Mayer & + \\
Esteroides & Lieberman Buchard & + \\
\hline
\end{tabular}


Tabla 5. Composición comparativa de algunos frutos (mg\%) (Base seca) $(*)$

\begin{tabular}{lccccccc}
\hline \multicolumn{1}{c}{ Fruto } & Calcio & Fósforo & Hierro & Tiamina & Riboflavina & Niacina & Vitamina C \\
\hline Camu-camu & 417,91 & 223,8 & 7,46 & 0,149 & 0,59 & 9,10 & 4149,22 \\
Capulí & 146,89 & 146,89 & 5,08 & 0,395 & 0,62 & 8,19 & -- \\
Pijuayo & 56,60 & 98,53 & 2,09 & 0,100 & 0,58 & 2,89 & 47,37 \\
Aguaje & 159,48 & 58,18 & 1,50 & 0,258 & 0,36 & 0,64 & -- \\
Tuna & 90,39 & 146,89 & 1,69 & 0.056 & 0,22 & 2,03 & 110,16 \\
Uvilla & 154,84 & 64,52 & 3,87 & 0,58 & 1,42 & 1,94 & 31,0 \\
\hline
\end{tabular}

$\left(^{*}\right)$ Estos valores fueron convertidos a extract o seco en base a los datos de la Tablas Peruana de Composición de Alimentos del Instituto nacional de Salud: $1996^{(8)}$.

fibra cruda 5,42 y carbohidratos 88,84. En base seca, en miligramos por ciento: vitamina $B_{1} 0,58$; vitamina $B_{2}$ 1,42; niacina 1,94 y vitamina $C$ 31,0. También presenta en base seca, en miligramos por ciento: calcio 154,84; hierro 3,87 y fósforo 64,52 .

Se ha detectado presencia de compuestos fenólicos, flavonoides, taninos y en menor cantidad alcaloides y esteroides.

\section{REFERENCIAS BIBLIOGRAFICAS}

1. Soukup J. Vocabulario de los nombres vulgares de la flora peruana y catálogo de los géneros. Editorial Salesiana. Lima, 1987.

2. Ministerio de Agricultura. La fruticultura en el Perú 1988-1998. Oficina de Información Agraria. Lima, 1998.

3. Pompa, G. Medicamentos Indígenas. $47^{\mathrm{a}}$ ed. Edit. América. Caracas, 1980.

4. AOAC. Official Methods of Analysis of the Association of Official Analytical Chemist, 15th ed; Arlington, VA. 1990.
5. Asociación de Químicos de Vitaminas. Métodos de análisis de vitaminas. Edit. Academia. León, 1969.

6. Chhabra S. Antibacterial activity of some Tanzanian plants used in traditional medicine. Fitoterapia 1991, 62:499-503.

7. Coee FG, Anderson GJ. Screening of medicinal plants used by the Garifuna of eastern Nicaragua for bioactive compounds. Journal of Ethnopharmacology 1996, 53:29-50.

8. Instituto Nacional de Salud. Tablas peruanas de composición de alimentos. $7^{\mathrm{a}}$ ed. Ministerio de Salud. Lima, 1996.

Manuscrito recibido el: 22/08/2011

Aceptado para su publicación el: 13/12/2011

\section{Correspondencia:}

Nombre: Gladys Constanza Arias Arroyo

Dirección: Av. Javier Prado Este 146o, Urb. Corpac, San Isidro - Lima

e-mail: ariasarroyo@gmail.com 